\title{
Claude Lévi-Strauss por Eduardo Viveiros de Castro
}

\author{
EDUARDO VIVEIROS DE CASTRO (ENTREVISTA)
}

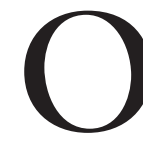

ETNÓLOGO brasileiro Eduardo Viveiros de Castro foi entrevistado por Marc Kirsch, diretor editorial de La Lettre du Collège de France, para o número especial da publicação comemorativo do centésimo aniversário de Claude Lévi-Strauss.

Etnólogo americanista, com experiência de pesquisa na Amazônia, Viveiros de Castro é doutor em Antropologia Social pela Universidade Federal do Rio de Janeiro (UFRJ) e tem pós-doutorado pela Université Paris X. É professor de Etnologia no Museu Nacional/UFRJ desde 1978 e membro da equipe de Recherche en Ethnologie Américaniste do CNRS desde 2001.

La Lettre - O centésimo aniversário de Claude Lévi-Strauss e a grande atenção que suscita revelam a posição excepcional que ocupa no mundo intelectual francês o autor de Tristes trópicos. Ele é celebrado hoje como uma das grandes figuras do pensamento do século XX, como se tivessem percebido de repente, com um misto de surpresa e de orgulho, que ele já fazia parte do panteão nacional. Mas no estrangeiro, e no Brasil, qual é a influência de Lévi-Strauss?

Eduardo Viveiros de Castro - Lévi-Strauss corresponde ao personagem clássico do intelectual francês, figura patrimonial que excede amplamente o quadro de sua disciplina, embora tenha sempre se preocupado em só falar como antropólogo.

O fato de que, por um concurso de circunstâncias, sua carreira esteja ligada ao Brasil parece dar aos brasileiros uma espécie de autoridade para falar de Lévi-Strauss, sobretudo em São Paulo, onde ele ensinou e descobriu sua vocação de antropólogo. Depois da tradução para o português de Tristes trópicos, os brasileiros começaram a se dar conta de sua existência e importância. Mas sua real influência começou a se fazer sentir no Brasil apenas nos anos 1960, no momento em que a antropologia se constitui em nossas plagas como uma disciplina autônoma: até então, ela era uma especialidade nos cursos de ciências sociais. Lévi-Strauss veio ao Brasil como professor de Sociologia: ensinava Mauss, Durkheim e Augusto Comte. Fez pesquisas em etnologia e formou alguns etnólogos, mas no quadro dos cursos de Sociologia da Universidade de São Paulo. Ele só passou a ser considerado de fato como etnólogo algum tempo depois da temporada no Brasil, durante o seu período nova-iorquino. Foi nos 
Estados Unidos que adquiriu sua verdadeira dimensão teórica, ao entrar em contato com Boas, Lowie, Kroeber e (sobretudo) Roman Jakobson. Mas ele já tinha em sua bagagem as pesquisas de campo e os materiais recolhidos junto aos Nambiquara e aos Bororo.

No Brasil, os cursos de Antropologia eram mais marcados pela escola americana, pela antropologia cultural. Ensinavam-se a Etnologia Indígena, a Arqueologia, a Antropologia Física e a Linguística em departamentos que seguiam o modelo instaurado por Franz Boas. A entrada em cena de Lévi-Strauss, já como antropólogo consagrado, abriu outras perspectivas: pertencendo ao mesmo tempo à escola francesa e à americana, ele soube relacionar várias tradições. Na origem, ele é um antropólogo social no estilo de Mauss e Durkheim, mas integrou igualmente a contribuição fundamental do pensamento americano de Boas e Lowie. Lévi-Strauss é o grande mediador ou "intercessor" da antropologia do século XX.

La Lettre - Às vezes lhe foi feita esta censura: na confluência de várias tradições, ele não se inscrevia em nenhuma e seria inclassificável.

$E V$ de $C$ - Prefiro a versão positiva desse julgamento. Evidentemente seria um erro fazer uma apologia exagerada de Lévi-Strauss e dizer que ele inventou a antropologia. Mas não seria injusto dizer que a reinventou. Ele não é simplesmente uma grande figura que se destaca dentro da história da antropologia vista como um percurso contínuo: é uma espécie de outsider, pois não pertence nem à escola inglesa, nem à escola americana, nem mesmo à escola francesa - já que se pode dizer que só houve verdadeiramente antropologia francesa depois de Lévi-Strauss. Antes dele havia, claro, a tradição do Museu do Homem, de Marcel Mauss, de Marcel Granet, de Paul Rivet, mas não se tratava de antropologia propriamente dita, que dialogasse em pé de igualdade com as tradições nacionais americana e britânica. Havia também Maurice Leenhardt ou Marcel Griaule, magníficos etnólogos, mas que não tinham o talento teórico nem a largueza de vistas de Lévi-Strauss.

Nesse sentido, pode-se dizer que Lévi-Strauss reinventou a antropologia. Ele foi o Boas e o Malinowski francês. Foi quem deu à antropologia francesa sua verdadeira dimensão teórica e institucional. Não fez escola, não tem discípulo: é antes um homem que se manteve a distância. No entanto, foi ele que criou a Antropologia Francesa como disciplina. O Laboratório de Antropologia Social é a primeira instituição antropológica, no sentido moderno do termo, na França.

La Lettre - Lévi-Strauss tem também uma dimensão literária e política.

$E V$ de $C$ - Tristes trópicos foi um livro revolucionário no que respeita à forma, sobretudo se não considerarmos simplesmente o estilo "literário", mas adotarmos um ponto de vista mais geral. Trata-se, no fundo, do relato de um trabalho de campo malogrado: é um livro paradoxal e inovador, pós-moderno bem antes da hora. Ou tome-se ainda, Raça e história, um opúsculo que teve um impacto considerável. 
Lévi-Strauss desempenhou um papel-chave na sedimentação de uma nova sensibilidade cultural (não apenas francesa, mas mundial) para com a questão da cultura, justamente. Ele transformou o "primitivo" do século XIX, personagem essencialmente negativa ou privativa, na figura positiva do "selvagem", devolvendo-lhe algo do papel que ele tinha no século XVI, ao retomar inspirações presentes em Montaigne e Rousseau, duas referências fundamentais em sua obra.

Lévi-Strauss é um grande intelectual, uma referência de seu tempo. Mas, paradoxalmente, sempre manifestou uma certa reticência em assumir esse papel de intelectual público. Com frequência evita pronunciar-se quando o pressionam a fazê-lo. Não gosta muito das situações em que lhe pedem para falar "em nome de". Em realidade, ele se recusa de maneira bastante sistemática a falar em nome do que quer que seja, a não ser, às vezes, da espécie humana - quando adota então aquele tom sombrio e pessimista dos moralistas do século XVIII. $\mathrm{O}$ interessante é que ele conseguiu tirar desse pessimismo efeitos notáveis de conhecimento.

La Lettre - No entanto, ele conhecen uma espécie de travessia do deserto. Sofreu, em particular, criticas dirigidas contra o estruturalismo e do refluxo dessa corrente.

$E V$ de $C$ - Claro, houve críticas. Por exemplo, dizem que o estruturalismo não se interessa pela história, não valoriza o papel dela para a práxis humana etc. Penso, ao contrário, que Lévi-Strauss é um homem obcecado pela história. A palavra e o tema da história retornam permanentemente em seus escritos. Ele fez contribuições fundamentais à história das sociedades ameríndias a partir de suas análises estruturais; seus trabalhos deram, além disso, um novo impulso à história do parentesco europeu.

Do mesmo modo, reprovam-lhe com frequência ser anti-humanista. No entanto, ele é alguém que fala constantemente da humanidade e da espécie humana. Apenas, ele quer separar a ideia de humanidade da ideia de sujeito. No final de $O$ pensamento selvagem, em um diálogo polêmico com o pensamento de Sartre, sustenta que é preciso ousar "empreender a resolução do humano em não humano". Isso equivalia, alegava Sartre, a estudar os homens como se fossem formigas: mas, explica Lévi-Strauss, "além de essa atitude nos parecer ser a de todo homem de ciência a partir do momento em que é agnóstico, ela não é muito comprometedora, pois as formigas, com seus cultivos artificiais de cogumelos, sua vida social e suas mensagens químicas, já oferecem uma resistência suficientemente coriácea aos empreendimentos da razão analítica...".

La Lettre - A questão do naturalismo e da relação entre natureza e cultura são grandes temas que atravessam a obra de Lévi-Strauss e que suscitaram muitos debates.

$E V$ de $C$ - A posição de Lévi-Strauss mudou bastante sobre esse ponto. Vemos na sua obra como a oposição entre natureza e cultura passa de uma 
universalidade objetiva, ou ontológica, poderíamos dizer, a uma universalidade subjetiva, ou antropológica. Ela cessa de ser uma oposição real para se tornar uma antinomia inerente à reflexão da humanidade sobre sua própria condição.

La Lettre - Deve-se ver nisso a herança de uma tradição cartesiana dualista que Lévi-Strauss assimilou durante sua formação filosófica?

$E V$ de $C$ - Lévi-Strauss afirma, em $O$ pensamento selvagem, que a oposição natureza/cultura, tão central em As estruturas elementares do parentesco, tinha para ele, agora, "um valor sobretudo metodológico". ${ }^{1}$ Posteriormente, em particular numa entrevista com Raymond Bellour, ${ }^{2}$ observa que foi na questão do estatuto da oposição entre natureza e cultura que o seu pensamento mudou de forma mais importante. No início, ele tratava a oposição como natural: agora, diz ele, vejo-a como cultural, embora permaneça universal. É um pouco como se Lévi-Strauss tivesse despertado de seu sono dogmático, percebendo a oposição natureza-cultura como, na verdade, uma espécie de ilusão necessária da razão. Ou seja, mesmo não sendo real, trata-se de uma oposição que a cultura não pode deixar de se colocar.

Em minha opinião, as coisas não são tão simples assim. Do mesmo modo que há sociedades cuja atitude em relação à história é fundamentalmente diferente da nossa, como afirma o próprio Lévi-Strauss, não haveria por que supor que todas as sociedades opõem natureza e cultura da mesma maneira que nós. Não é que as sociedades diferentes das nossas não façam nenhuma diferença entre uma ordem humana e uma ordem não humana: simplesmente a diferença não faz exatamente a mesma diferença que entre nós.

Por fim, parece-me que para Lévi-Strauss essa oposição aparece menos como um ponto de chegada do que como um instrumento para seguir adiante. Ele mostra, por exemplo, que a mitologia sul-americana está focalizada nessa oposição, mas, se examinarmos mais de perto, ela se deixa multiplicar e declinar em outras oposições. É uma característica do pensamento dele: para LéviStrauss, um contraste binário nunca é um objeto simples, quero dizer um objeto simplesmente duplo. A uma pergunta sobre o futuro da antropologia, ele respondeu um dia: "você sabe, sempre se diz 'das duas, uma', e há sempre uma terceira coisa”. O mesmo acontece com a oposição natureza-cultura: é arriscado escolher uma das duas, pois as coisas interessantes se passam entre as duas, lá onde as duas estão se comunicando.

La Lettre - Uma glândula pineal antropológica, em suma, que ligaria dois elementos lógica ou ontologicamente incompatíveis?

$E V$ de $C$ - A oposição só é colocada para fazer valer esses fenômenos cujo interesse reside no fato de não serem nem inteiramente natureza, nem inteiramente cultura, mas de fazerem a conexão entre as duas - conexão sempre inacabada, imperfeita, desequilibrada. E há uma questão suplementar. Pergunta-se o que veio primeiro: a oposição ou o elemento que faz a ligação, a oposição sendo colocada apenas para mostrar afinal que ela não funciona. Lévi-Strauss 
só coloca a oposição natureza-cultura para acrescentar em seguida, com aquela espécie de maneirismo que lhe é habitual, "isso não é tudo", como faz com frequência ao final de uma demonstração complicada, quando pensamos que ele conseguiu fechar um circuito argumentativo e dar uma coerência sistemática à sua apresentação. Basta então, para repor em marcha o pensamento, uma destas pequenas frases: "mas há mais". E logo se abrem novos caminhos ainda não percebidos.

\section{La Lettre - Qual foi para o senhor a influência de Lévi-Strauss?}

$E V$ de $C$ - Tive poucos contatos pessoais com ele: dois ou três encontros, algumas trocas de correspondência. Mas ele sempre se mostrou de uma grande generosidade para com o meu trabalho, ao qual chegou a fazer referências que me emocionaram muito. Ele é um homem de uma rara cortesia, e não menos incomum elegância.

O mais importante para mim é que devo a Lévi-Strauss a minha escolha profissional. Cheguei à etnologia por vias transversas. Primeiro fui sociólogo, nos anos 1960. Interessava-me por teoria literária e conheci um grande professor (Luiz Costa Lima) que lia Lévi-Strauss na perspectiva da análise do discurso. Foi ao participar de grupos de trabalho sobre as Mitológicas que descobri que havia índios no Brasil: os cursos de sociologia não os mencionavam, exceto a título de vestígios de um passado distante. A sociologia brasileira estava focalizada em alguns grandes temas: as cidades, a industrialização, a formação da classe operária, o campesinato etc. Os índios praticamente não tinham lugar nesse esquema. Os que ainda existiam estavam se tornando camponeses ou apareciam como resíduos de um período ultrapassado da história do país.

Quando me dei conta de que esses índios ainda existiam e tinham um discurso de uma grande riqueza, filosoficamente fascinante, decidi fazer um doutorado em Antropologia. Lévi-Strauss me converteu à antropologia. Seu nome e sua obra têm para mim, portanto, um valor pessoal.

La Lettre - Pode-se ainda ser antropólogo da mesma forma que na época de Lévi-Strauss?

$E V$ de $C$-Sim e não. Tomemos os mitos. Nas Mitológicas, ele trabalha a partir de mitos orais, recolhidos por etnógrafos, viajantes etc., que os haviam traduzido ou recolhido sob forma traduzida - por índios bilíngues, por exemplo. Hoje vemos aparecer compilações de mitos escritos pelos próprios índios. Esses continuam, porém, a apresentar as mesmas variações e a mesma dinâmica de transformação que os mitos que Lévi-Strauss mostrou serem, na verdade, apenas transformações uns dos outros. Na verdade, quando um grupo produz um livro de mitos, algum tempo depois um outro grupo produzirá, por sua vez, um livro para dar sua versão e apresentar o "verdadeiro" modo de contar os mitos em questão. Graças a essas rivalidades, vemos se produzirem exatamente as mesmas operações de transformação, de inversão etc., que procedem da natureza mesma do mito, segundo Lévi-Strauss. Assim, a conversão da mitologia 
Lévi-Strauss com a equipe da Expedição à Serva do Norte.

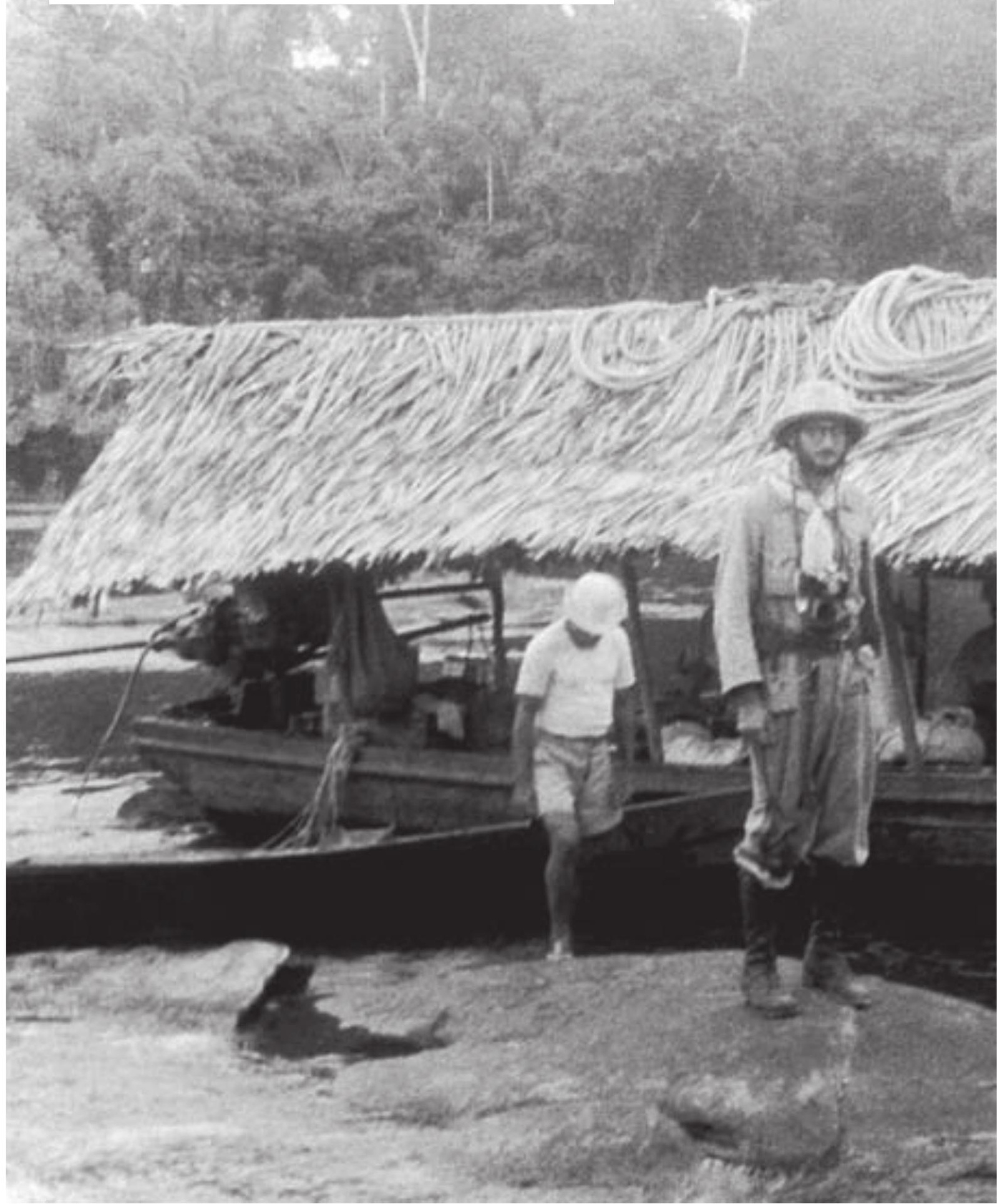


em literatura indígena não mudou o método a empregar; mas de todo modo ela mudou a situação. Os índios começam a controlar os instrumentos do seu próprio conhecimento, da sua própria colocação em discurso. Eles produzem mitos que não são mais os mesmos de outrora, mas que podem ser analisados como o fazia Lévi-Strauss. Só que há um nível suplementar, pois se dispõe agora de uma espessura histórica nova: as fontes antigas podem daqui por diante ser comparadas às fontes produzidas pelos próprios índios, isto é, a todo um conjunto de elementos dos quais Lévi-Strauss não dispunha. O conhecimento sobre os índios da Amazônia aumentou enormemente: o que se sabia na época das Mitológicas representa menos de $30 \%$ do que se sabe hoje.

La Lettre - Será que a antropologia se reaproxima do sen objeto e deixa de se conceber como o estudo de sociedades exóticas e estranbas?

$E V$ de $C-A$ ideia de que a condição do saber antropológico é um estado de não relação objetiva entre o antropólogo e seu objeto está hoje ultrapassada. A diferença se interiorizou. Lévi-Strauss disse isso em Raça e história. Vemos uma espécie de exotização que cresce para dentro. Nossa sociedade torna-se cada vez mais estranha dentro dela mesma, em todos os sentidos do termo: bizarra, dividida, não coincidente consigo, estrangeira. A globalização redistribuiu as cartas. Os africanos não estão mais apenas na África: estão também na Europa, nos Estados Unidos etc.; o mesmo em relação às populações da Ásia e da Oceania.

La Lettre - Tristes trópicos se apresenta como um testemunho nostálgico sobre um mundo em via de desaparecer, com a ideia de que a assim chamada civilização destrói a diversidade cultural, assim como destrói os biótopos.

$E V$ de $C$ - Lévi-Strauss parece pensar que a espécie está vivendo seus últimos séculos, que ela causa danos irreversíveis ao meio ambiente e aos mundos não humanos. Certamente sabemos que nossa espécie conseguiu sair de situações que eram provavelmente piores, mas há, de fato, motivos de sobra para inquietação. A demografia é um deles, e é um tema bastante presente em LéviStrauss. O malthusianismo, claro, tem má fama. Para a minha geração, sobretudo no Brasil, ele era visto como um discurso de direita: devia-se combatê-lo, apoiar as fontes vivas das forças populares. Mas como gerir a expansão demográfica agora, que a superpopulação é obviamente um perigo para nós mesmos? É possível que estejamos realmente diante de um impasse antropológico, que é também um impasse biológico, planetário, cosmológico. A distinção entre natureza e cultura se apagou de forma dramática: se havia dúvidas sobre o fato de essas duas "ordens" estarem totalmente imbricadas, agora não há mais. Vemos que a cultura é uma força natural, e que a natureza está tão envolvida em redes culturais, que é absurdo tentar distingui-las.

Pode acontecer que sejamos a única espécie que vai se extinguir sabendo disso, mesmo não querendo acreditar inteiramente nisso - pelo menos não o bastante para mudar alguma coisa, na medida em que isso seja ou fosse possível. 
Mas vemos ao mesmo tempo como vai se desenvolvendo todo um imaginário em torno da salvação da espécie, uma literatura pós-humanista, tecnófila, à maneira de Kurzweil, dos ciberpunks etc., que propõem escatologias transfiguradoras. Não temos mais grandes mitologias: elas desapareceram ou se transformaram em (mau) tratado de sociologia. A ficção científica é a metafísica popular do nosso tempo, nossa nova mitologia.

Lévi-Strauss provavelmente percebeu essa evolução, daí sua insistência, em $O$ pensamento selvagem, na convergência entre o pensamento selvagem e a vanguarda da ciência da sua época, a cibernética, a teoria da informação etc. Parece que o mais primitivo e o mais avançado se juntam desde a grande época da modernidade, os séculos XIX e XX. É uma forma de anunciar as correntes contemporâneas em favor do homem natural tecnicizado e a convergência, manifesta em algumas correntes do pensamento de esquerda americano, entre neoprimitivismo e tecnofilia, o que geralmente é apresentado como uma tomada em mãos por nossa espécie de seu próprio destino por meio da tecnologia. Mas poderia ser apenas a convergência acidental de caminhos que se cruzam... Gosto da ideia de que o Ocidente é um acidente, e de que ele acabará talvez por alcançar, graças à ponta mais avançada da sua tecnologia, a matriz antropológica universal da qual saiu, uma espécie de tendência natural da espécie. É nisso que se inspiram as correntes pós-humanistas. Trata-se, é claro, de uma ficção, completamente utópica.

É impressionante que nessas correntes, como muitas vezes no pensamento contemporâneo, um dos pontos comuns seja o monismo. Todos estão de acordo em combater o dualismo: é preciso criar o $u m$, ainda que não haja acordo sobre sua natureza. Os criacionistas são monistas, os cientistas são igualmente monistas. Mas o monismo me parece sempre ser uma espécie de dualismo escondido. Gilbert Simondon observava que todo monismo é um dualismo do qual se fez desaparecer um dos ramos integrando-o no outro: um dualismo que não ousa dizer seu nome, que escamoteou uma metade da realidade. O que faz o materialismo clássico quando diz que o espírito não é mais que matéria, senão fazer desaparecer o espírito metendo-o na matéria? O mesmo acontece no discurso sobre o corpo, notadamente em fenomenologia. O corpo é o novo nome do espírito. Tudo que se atribuía ao espírito é agora o corpo que faz. O cérebro é o nome moderno do espírito. Essas questões estão presentes em Lévi-Strauss, evidentemente.

La Lettre - Para quem o ouve, a antropologia, que partiu da filosofia, com Lévi-Strauss, parece voltar a ela.

$E V$ de $C$ - Tim Ingold, um antropólogo inglês, tem uma bela definição: Anthropology is philosophy with the people in. A antropologia é filosofia que não deixa as pessoas de fora, que aborda os problemas tais como se colocam na realidade dos que os colocam e os vivem. A fórmula se aplica bem a Lévi-Strauss. Ele teve o mérito de não cortar o vínculo entre antropologia e filosofia - em- 
bora dissesse o contrário. Ele tomou suas distâncias em relação à filosofia, mas faz constantemente filosofia por intermédio da sua antropologia. Ele utiliza a antropologia como uma máquina de guerra contra a filosofia, o que é, afinal de contas, um projeto filosófico. Nele, o retorno às coisas mesmas não passa pela fenomenologia, ${ }^{3}$ mas pela etnologia. É preciso ir longe para voltar às coisas mesmas.

Notas

l Cf. La pensée sauvage. Paris: Plon, 1962a. p.294.

2 A propósito de "La voie des masques", ver: Oeuvres. Paris: Gallimard, 2008. p.165465 .

3 "Em vez de abolir a metafísica, a fenomenologia e o existencialismo introduzem dois métodos para lhe encontrar álibis” (Tristes tropiques, 1955, p.61).

Eduardo Viveiros de Castro é professor do Museu Nacional da Universidade Federal do Rio de Janeiro. É autor, entre outros, de A inconstância da alma selvagem (CosacNaify). @ - eviveirosdecastro@gmail.com

Publicado em Hors Série - La Lettre du Collège de France, Claude Lévi-Strauss - Centième anniversaire, Novembre 2008. Entrevista concedida a Marc Kirsch. Tradução de Paulo Neves. O original em francês - "Claude Lévi-Strauss vu par Eduardo Viveiros de Castro" - encontra-se à disposição do leitor no IEA-USP para eventual consulta.

Recebido em 16.7.2009 e aceito em 21.8.2009. 